\title{
O PODER NA FRAQUEZA: O PARADOXO DA PALAVRA DA CRUZ, ESTUDO DE 1COR 1,18-25
}

Power in Weakness: the Paradox of the Word of the Cross, a Study on 1Cor 1:18-25

José Adriano Filho *

RESUMO: Em 1Cor 1,18-25 Paulo apresenta o contraste entre duas formas de compreender a sabedoria e o poder. A primeira delas, como ele os compreende, é revelada pela proclamação da cruz de Cristo. A segunda forma, a perspectiva de algumas pessoas de Corinto, era mais a eloquência humana, adquirida por meio do treinamento retórico, incluindo também a performance do orador. Para Paulo, a palavra da cruz indica o aspecto decisivo da identidade cristã. A discussão destes temas em conexão com os grupos que compunham a comunidade é também significativa, pois a situação retórica envolvida conecta a sabedoria com as divisões e status social. 1Cor 1,18-25 é um discurso sobre as origens da comunidade, isto é, a "palavra da cruz", a mensagem que Paulo proclamou aos coríntios quando a comunidade foi fundada. Numa situação de partidarismos, a cruz, além de ser o elemento unificador da comunidade cristã, era também sua marca distintiva como um sistema alternativo de valores.

PALAVRAS-CHAVE: Palavra da Cruz. Sabedoria e poder. Comunidade Cristã.

ABSTRACT: In 1Cor 1:18-25, Paul presents the contrast between two ways of understanding wisdom and power. The first one, according to him, is revealed in the cross of Christ. The second, according to some Corinthians, refers to the human eloquence acquired through rhetorical training, including the orator's performance. For Paul, the word of the cross is the main aspect of Christian identity. The discussion of such topics with the groups that made up the community is also significant, because the rhetorical situation involved connects wisdom with

* Faculdade Unida de Vitória, Vitória, ES, Brasil. 
divisions and social status. 1Cor 1:18-25 is a discourse on Christian community origins, that is, the "word of the cross", the message that Paul proclaimed to the Corinthians when the community was founded. In a context marked by partisanship, the cross is the unifying element of the Christian community, as well as its distinctive mark as an alternative system of values.

KEYWORDS: Word of the Cross. Wisdom and Power. Christian Community.

\section{Introdução}

A "palavra da cruz", uma sinédoque que Paulo utiliza para a narrativa Ado evangelho em sua totalidade e que inclui a morte e ressurreição de Cristo, estabelece "uma nova forma de ser no mundo" (MITCHELL, 1994, p. 70). A cruz não é somente "o remédio e expiação dos pecados passados, mas a base da identidade da comunidade cristã, cujo poder transformador dá forma à sua existência no presente e no futuro" (SANDERS, 1977, p. 465-566). O fato de algumas pessoas de Corinto, cujo "mundo" não fora ainda transformado, considerarem a palavra da cruz como loucura $(1,18.21 .23)$ introduz uma dimensão epistemológica na discussão deste tema, pois estabelece uma conexão entre a cruz e a escatologia. Havia, em Corinto, um conhecimento "segundo a carne", mas em meio às lutas e realidades da existência cristã, antes que o eschaton irrompa-se em sua totalidade, o que se opõe a este tipo de conhecimento não é o conhecimento "segundo o Espírito", mas o conhecimento "segundo a cruz". As pessoas que reconhecem que suas vidas constituem uma dádiva de Deus, vividas na tensão entre o "já" e o "ainda não" do reino, reconhecem que até a irrupção total do novo tempo o conhecimento "segundo o Espirito" deve ocorrer somente "segundo a cruz" (THISELTON, 2000, p. 147). A "palavra da cruz" conduz seus destinatários a uma crise fundamental, tornando-os "os que estão perecendo" ou, então, "os que estão sendo salvos" $(1,18)$. Como estes termos têm também um grande significado escatológico, o julgamento esperado para o eschaton já ocorre na palavra cruz (VOSS, 2002, p. 64).

A "palavra da cruz" envolve o reconhecimento da morte e ressurreição de Cristo como os eventos centrais de uma história cósmica que fundamenta a existência da comunidade cristã e apostólica. Por esta razão, ao tratar do tema da sabedoria em sua resposta aos problemas de divisão na igreja de Corinto, Paulo apresenta o contraste entre duas formas de compreendê-la: uma, como ele a entende, é revelada na cruz de Cristo; a outra, como algumas pessoas de Corinto a viam, era mais a eloquência humana, adquirida por meio do treinamento retórico, incluindo a apresentação pública do orador. O tema da sabedoria tem um papel relevante no discurso de Paulo, pois para ele as pessoas que estavam envolvidas nas divisões tinham 
adotado o modus operandi da "sabedoria deste mundo". Paulo também argumenta, com o apoio das Escrituras Judaicas, que o que Deus sempre pretendera fazer Ele agora o realizou na crucificação de Cristo: o fim da autossuficiência que se manifesta nas ações da sabedoria humana.

"Sabedoria", "status social e poder", "honra" eram valores bastante apreciados pelos coríntios. Estes fatores podem ser explicados socialmente, mas o problema envolve também a compreensão da "palavra da cruz". É preciso compreender o significado da cruz de Cristo, um aspecto que se reflete na questão central que Paulo apresenta: "Acaso o Cristo está dividido? Porventura foi Paulo crucificado em favor de vós? Foi acaso em nome de Paulo que fostes batizados?" (1,13). A resposta de Paulo aos valores do milieu cultural dos coríntios parte da perspectiva da cruz. Desta forma, em 1Cor 1,18-25 Paulo destaca os temas sabedoria e loucura, fraqueza e poder devido a visões diametralmente opostas sobre este tema em Corinto. O seu argumento é teológico, mas a crise dos coríntios tinha raízes na sua realidade social. Paulo procura inverter o ethos social das pessoas envolvidas nas divisões. A sua aproximação retórica é compreensível e, caracteristicamente, paradoxal (SHI, 2009, p. 82-84).

\section{Texto e desenvolvimento de 1Cor 1,18-25}

1Cor 1,18-25 distingue-se do texto que o precede $(1,10-17)$ e do texto que o sucede $(1,26-31)$. Em 1,18, a partícula "pois" estabelece a ligação com o texto que precede e, em 1,26, a introdução do verbo na segunda pessoa do plural: "Considerai" $(1,26)$, dá início a um novo tópico: a vocação dos coríntios é um exemplo da loucura e fraqueza de Deus (1,26-31). 1Cor 1,18-25 gira em torno das polaridades sabedoria/loucura e poder/fraqueza. Do ponto de vista da "sabedoria deste mundo", a cruz significa indignidade, humilhação, fraqueza e loucura; do ponto de vista de Deus, significa sabedoria e poder: a "fraqueza" é "poder" e a "loucura" sabedoria, um paradoxo que é definido escatologicamente em relação à cruz de Cristo.

Texto de 1Cor 1,18-25:

${ }^{18}$ Com efeito, a palavra da cruz é loucura para os que estão sendo destruídos, mas para nós, que estamos sendo salvos, é o poder de Deus. ${ }^{19}$ Pois está escrito: 'Destruirei a sabedoria dos sábios, e a inteligência dos inteligentes anularei'. ${ }^{20}$ Onde está o sábio? Onde está o escriba? Onde está o inquiridor deste século? Porventura, não tornou Deus louca a sabedoria do mundo? ${ }^{21}$ Pois desde que, na sabedoria de Deus, o mundo não conheceu a Deus por sua sabedoria, pareceu bem a Deus salvar aos que creem pela loucura da pregação. ${ }^{22}$ Porque os judeus pedem sinal, e os gregos buscam sabedoria. ${ }^{23}$ Nós, porém, anunciamos Cristo crucificado, escândalo para os judeus e loucura para os gregos, ${ }^{24}$ mas para os que são chamados, judeus e gregos, Cristo, poder e sabedoria de Deus. 
${ }^{25}$ Porque a loucura de Deus é mais sábia do que os homens, e a fraqueza de Deus é mais forte do que os homens.

1Cor 1,18-25 inicia-se com a apresentação do contraste fundamental entre as perspectivas humana e divina e está estruturado em torno de várias antíteses. Em 1,18a/18b; 1,22/23a e 1,23b/24 as oposições expressam-se na forma de paralelismos antitéticos. Na declaração de abertura: "A palavra da cruz é, pois, loucura para os que estão sendo destruídos, mas para nós, que estamos sendo salvos, é o poder de Deus" $(1,18)$, o contraste é destacado pelo uso das partículas "pois", "mas", e a repetição do verbo "é" como ligação nas duas linhas do verso. Destacam-se as respostas diametralmente opostas dos dois grupos mencionados, provocadas pela "palavra da cruz": "loucura" ou "poder de Deus", e dois tipos de efeito, assinalados pelo duplo uso do verbo "é" com dativo: "os que estão sendo destruídos" e "os que estão sendo salvos". Os recipientes da palavra da cruz estão divididos entre "os que estão sendo destruídos" e "os que estão sendo salvos", "mundo" e "os que creem", "judeus e gregos" e "os que são chamados" (POGGEMEYER, 2005, p. 54-55; INKELAAR, 2011, p. 171-172).

O texto apresenta também um desequilíbrio entre os termos opostos da sua estrutura antitética: loucura $(1,18 a)$ contrasta com poder (18b), não com sabedoria, como era de se esperar. $\mathrm{O}$ acento está na segunda linha do verso, por meio da adição de "nós", "os que estão sendo salvos", "Deus" e "poder". A segunda linha supera a primeira linha do verso e dá continuidade ao argumento apresentado. Este modelo continua nos dois paralelismos de 1,22-24: (a) Porque os judeus pedem sinal, e os gregos buscam sabedoria (b) Nós, porém, anunciamos Cristo crucificado, (a') escândalo para os judeus e loucura para os gregos, $\left(b^{\prime}\right)$ mas para os que são chamados, judeus e gregos, Cristo, poder e sabedoria de Deus; estas antíteses derivam do contraste entre "sabedoria da palavra", "sabedoria do sábio", "sabedoria do mundo" e "a loucura da palavra da cruz" (CONZELMANN, 1975, p. 41-42; INKELAAR, 2011, p. 172).

Paulo aplica também o contraste entre as perspectivas humana e divina sobre a "palavra da cruz" à sabedoria ao citar um texto profético que denuncia os que confiam na sua própria capacidade para alcançá-la (Is 29,14). A fórmula: "Pois está escrito", introduz a citação da Escritura: "Destruirei a sabedoria dos sábios, e a inteligência dos inteligentes anularei" $(1,19)$, que é seguida pelas perguntas retóricas: “Onde está o sábio? Onde está o escriba? Onde está o inquiridor deste século? Porventura, não tornou Deus louca a sabedoria do mundo?" $(1,20)$. Há também uma correspondência entre 1,18 e 1,21: "loucura" (1,18a) corresponde à "falta de conhecimento" $(1,21 a)$, "os que estão sendo salvos" $(1,18 b)$ corresponde a "salvar os que creem" (1,21b). A "palavra da cruz" desprezada como "loucura" (1,18a) é anunciada como meio de salvação $(1,21 b)$. A citação da Escritura não 
diminui o poder retórico do desenvolvimento da argumentação apresentada. Ela menciona grupos sociais de prestígio, como "sábio", "escriba" e "inquiridor", e as formas verbais "destruirei", "anularei", "tornarei louca" expõe a nulidade destes grupos quando vistos da perspectiva da cruz. Esta linguagem radical deriva do discurso profético, o discurso divino em primeira pessoa, e as questões apresentadas contrastam com as longas sentenças do contexto, enquanto o gênero deliberativo da unidade maior manifesta-se no uso das antíteses, indicadas por "pois", "desde que", "porque" (INKELAAR, 2011, p. 172-173).

Destaca-se também no texto a presença do paradoxo: "Porque a loucura de Deus é mais sábia do que os homens, e a fraqueza de Deus é mais forte do que os homens" $(1,25)$. A "fraqueza" da cruz era uma realidade para Paulo (2Cor 12,4), mas em 1,25 ele não fala da fraqueza de Cristo e, sim, da "fraqueza de Deus", convertendo-a em paradoxo. A fraqueza torna-se um princípio: "o poder se aperfeiçoa na fraqueza" (2Cor 12,9). Os termos paralelos "loucura" (1,25a) e "fraqueza" $(1,25 b)$ são também usados da mesma forma, pois apresentam a perspectiva e experiência do mundo sobre a crucificação do Messias. "Deus" e "loucura" não caminham juntos, então estamos diante de um paradoxo, e o texto procura levar os destinatários a modificar as suas convicções sobre o que significa ser sábio e o que é loucura segundo Deus. O paradoxo reafirma e sumariza o argumento apresentado em 1,18-24 referente à loucura da palavra de cruz e do Messias crucificado (INKELAAR, 2011, p. 173; FEE, 1984, p. 77).

Cada um dos versos de 1Cor 1,18-25 estabelece também o fundamento para o verso seguinte por meio das conjunções "pois", "desde que", "com efeito" e "porque" (1,19.21-25). Os temas sábio/sabedoria e loucura unem cada um dos versos que compõem a perícope (1,18-19.20-21.23-25). Após estabelecer a natureza essencial deste contraste, Paulo aplica-o à sabedoria ao citar as Escrituras Judaicas e extrair as implicações da citação a partir de três questões retóricas, nas quais censura o "sábio", o "escriba" e o "inquiridor deste século" $(1,20)$. 1Cor 1,21, que desenvolve ainda mais o argumento apresentado, está conectado com as questões retóricas apresentadas e explica porque "Deus tornou louca a sabedoria do mundo". A cláusula subordinada "desde que" $(1,21)$ estabelece o fundamento para a ação de Deus definida na cláusula principal. A declaração "por meio da loucura da pregação" é paralela a "pareceu bem a Deus salvar os que creem pela loucura da pregação", tornando clara a ligação entre 1,18 e 1,21: a "loucura da pregação" relembra "a palavra da cruz". Paulo identifica também "judeus" e "gregos" como pares complementares, contrastando-os com o critério que conduz ao conhecimento de Deus $(1,23)$. O foco, mais a pessoa crucificada do que a crucificação, define ainda mais o escopo do que significa "os que estão sendo destruídos" e amplia o pensamento de 1,18 referente à palavra da cruz da pespectiva dos que "estão sendo salvos": "Cristo, "poder e sabedoria de Deus" $(1,24)$. 
1Cor 1,25 indica que Deus estabeleceu um tipo de sabedoria que contradiz os padrões humanos de sabedoria. A "palavra da cruz" provoca uma inversão nos valores conectados com a perspectiva da sabedoria humana (POGGEMEYER, 2005, p. 48).

\section{A palavra da cruz, loucura que é poder}

A "palavra da cruz" era o centro da proclamação de Paulo e o seu objetivo era estabelecê-la como base da vida comunitária (1,10-17). O seu discurso contra as divisões na igreja de Corinto inicia-se com uma explicação da razão de o Evangelho entrar em conflito com a sabedoria deste mundo. A discussão apresentada está construída em termos de uma oposição entre Deus e o mundo, que se manifesta nos valores apresentados na antítese poder-fraqueza, embora Paulo atribua um significado positivo a estes termos ao apresentar a revelação paradoxal do poder de Deus na fraqueza da cruz (PICKETT, 1997, p. 64-65). Na declaração: "A palavra da cruz é, pois, loucura para os que estão sendo destruídos, mas para nós, que estamos sendo salvos, é o poder de Deus" $(1,18)$, o contraste assinalado pelas expressões "os que estão sendo destruídos" e "os que estão sendo salvos", é crucial para o argumento apresentado porque estabelece a discussão da oposição entre a "sabedoria de Deus" e a "sabedoria deste mundo" (THISELTON, 2000, p. 158; PICKETT, 1997, p. 66-67).

A cruz inaugura a "nova era" e a "loucura da cruz" pertence, agora, à forma de pensar dos "que estão sendo destruídos". "A expressão "os que estão sendo salvos", e Paulo inclui a si mesmo neste grupo (2Cor 2,15), indica o tema central da identidade cristã e a conexão com os grupos que compunham a comunidade é significativa, pois a situação retórica envolvida conecta a sabedoria com as divisões (1,11-13) e status social $(1,26-28)$. Os coríntios estavam acolhendo valores da sua identidade social, especialmente uma compreensão de "sabedoria" que em seu contexto social greco-romano referia-se tanto à posse de um conhecimento exaltado quanto à habilidade de expressar aquele conhecimento numa forma eloquente $\mathrm{e}$ poderosa. Estes valores precisavam ser avaliados da perspectiva da palavra da cruz. Para persuadi-los a mudar estes valores, Paulo apela à narrativa das origens da comunidade: a mensagem que ele thes proclamou quando a comunidade foi fundada: "Jesus Cristo, e este crucificado" (FIORENZA, 1987, p. 386-403; POGOLOFF, 1992, 71-95; SHI, 2009, p. 88-89).

A narrativa sobre um Messias crucificado era escandalosa para os judeus, e ofensiva para os gentios $(1,23)$. A morte de Jesus não era considerada como uma morte exemplar, segundo os padrões de pensamento do mundo greco-romano. No mundo antigo, a tradição da morte nobre, que ocorria numa ocasião de grande demonstração de coragem, na batalha ou em ou- 
tro tipo de serviço à pátria, era considerada uma honra especial (SEELEY, 1990, p. 83-141). A morte pela crucificação, por sua vez, uma forma de punição política ou punição decorrente de rebelião militar, não deixava chance para a pessoa recuperar a honra e o bom nome.

Para os romanos, a crucificação era uma punição comumente imposta às classes mais baixas da sociedade, ou seja, escravos, criminosos perigosos e rebeldes das províncias. Acompanhada de flagelação e outros tipos de tortura, a morte na cruz era considerada a mais cruel, a mais repugnante e mais extrema forma de punição. Envolvia a exibição pública e a submissão das vítimas a grande indignidade. As vítimas eram amarradas ou pregadas à cruz e deixadas a morrer à vista dos transeuntes, como exemplos para que a ordem e o governo romanos não fossem transgredidos. As vezes, a morte ocorria muitos dias depois e, frequentemente, as vítimas não tinham um funeral próprio. Elas eram difamadas social e eticamente pela consciência popular. A morte de Jesus na cruz foi uma experiência de total humilhação e ele foi despojado da sua honra e seu lugar na sociedade e na memória social (SHI, 2009, p. 20-39; HENGEL, 1977, p. 87-88).

No mundo greco-romano do primeiro século, dominado pelo amor à honra, a cruz representava a degradação e vergonha pública de uma pessoa nos limites da imaginação cultural. Então, o fato de que Paulo decidiu saber apenas "Jesus Cristo, e este crucificado" $(2,2)$, entre os coríntios, deve ter provocado escândalo, pois ninguém ousaria reivindicar que uma pessoa que fora punida com a morte na cruz era o Messias esperado. Como alguém poderia ser considerado poderoso, se sofreu a mais degradante morte nas mãos dos romanos? Paulo proclamou a "palavra da cruz" em diversas regiões do Império Romano e muitas pessoas sabiam que Jesus fora condenado como criminoso e crucificado. Desta forma, a afirmação de que Jesus crucificado era, de fato, o Messias seria entendida como loucura, pois não combinava com as expectativas correntes sobre o que era considerado como honra e prestígio. A declaração de que a "palavra da cruz é loucura para os que estão sendo destruídos" expressa a dura experiência de pregação missionária de Paulo e a ofensa que ela causava. Ele tem este ethos social em mente e a proclamação da cruz inverte as narrativas culturais da época que envolviam a eloquência e, em geral, estavam centralizadas na vida de pessoas sábias e poderosas (SHI, 2009, p. 39-41; HENGEL, 1977, p. 22-34; POGOLOFF, 1992, p. 119-121) ${ }^{1}$.

\footnotetext{
${ }^{1}$ JUDGE, E. A. The Reaction against Classical Education in the New Testament. Journal of Christian Education, v. 77, 1983, p. 14, declara: "The value system upon which Greek education had been built up is deliberately overthrown. Paul reacts powerfully against the perversion of human relations which he saw inculcated by the ideals of higher education. It was a perversion because it enshrined the beautiful and the strong in a position of social power. In his own case he deliberately tore down the structure of privilege with which his followers wished to surround him".
} 
A perspectiva "deste mundo" vê a cruz como espetáculo de indignidade, humilhação, fraqueza e loucura; a perspectiva divina a vê como o poder salvador de Deus. A cruz é poder de Deus, pois nela a promessa e ação salvadora de Deus tornam-se efetivas (THISELTON, 2000, p. 156-157). Paulo depende da proclamação da cruz para anunciar a transformação dos seus ouvintes. Ele vivia numa era apocalíptica e tinha algumas convicções apocalípticas fundamentais. A palavra da cruz tem um poder escatológico crítico que conduz aqueles que nela creem à nova criação de Deus representada na cruz. No pensamento apocalíptico, a era presente é caracterizada pelo mal e pela injustiça em antecipação à era futura, a idade da justiça e de paz. Fundamentalmente, Paulo acredita que os seres humanos estavam sob o poder de poderes anti-humanos e antidivinos. Eles não têm capacidade de se libertar do domínio destes poderes e de seus efeitos sempre crescentes. A solução é a cruz de Cristo, início da "nova criação" (Gl 1,5; 2Cor 5,17). A cruz de Cristo é tanto o ato apocalíptico de Deus quanto o ato do servo sofredor, humano, destinado a redimir ou libertar a humanidade dos poderes que a escraviza. A nova criação é inaugurada por Deus e por um ser humano representativo, Jesus, o Messias (GORMAN, 2001, p. 102-107).

A "palavra da cruz" revela o poder cruciforme de Deus, cujo modus operandi nela se manifesta. Ela indica o destino dos que "estão a caminho da ruína" e dos que "estão sendo salvos". Para justificar esta declaração, Paulo apela à autoridade das Escrituras Judaicas, importante marca da sua inventio retórica (COLLINS, 1999, p. 94-95). A citação da Septuaginta de Isaías 29,14 em 1,19, retirada de um oráculo de julgamento contra Jerusalém, que falhara e não compreendera a palavra e ação do Senhor, destaca o papel das Escrituras no desenvolvimento do argumento apresentado. $\mathrm{O}$ oráculo de Isaías indica que a sabedoria dos conselheiros que haviam orientado o rei a confiar no apoio militar do Egito seria reduzida a nada. A citação, introduzida pela fórmula "Pois está escrito", apresenta uma pequena diferença em relação à citação da Septuaginta de Is 29,14. Como forma enfática de conclusão, Paulo substitui o verbo "ocultarei" por "anularei", ficando o seu texto da seguinte forma: "Destruirei a sabedoria dos sábios, e a inteligência dos entendidos anularei" (HEIL, 2005, p. 17-19).

A citação fundamenta a declaração de que o que Deus realizou na sua sabedoria, a cruz de Cristo, desafia a compreensão que se baseia nos padrões da "sabedoria deste mundo" $(1,21)$. A "palavra da cruz" é o poder que, de acordo com a citação da Escritura, destruirá "a sabedoria do sábio". Esta destruição é indicada pelas três perguntas retóricas: "Onde está o sábio? Onde o escriba? Onde o inquiridor deste século?" (1,20a), por meio das quais Paulo convida os coríntios a perceber qual é o destino da "sabedoria deste mundo" à luz da ação salvadora de Deus na cruz de Jesus, o Messias. Os romanos eram atraídos por um tipo de sabedoria que qualificava as pessoas como figuras públicas competentes, um valor muito 
acentuado na tradição retórica. Ser "sábio segundo este mundo" envolvia o treinamento na arte retórica e está relacionado com educação, riqueza, nascimento e relações sociais (POGOLOFF, 1992, p. 126-127; THISELTON, 2000, p. 162). O escriba, uma pessoa letrada, um especialista, era comumente um "secretário" ou funcionário de uma guilda oficial ou bureau público no mundo grego-romano. A palavra "inquiridor", "debatedor", "orador" indica as pessoas hábeis que participavam em disputas, nos debates nos tribunais e recitações nos banquetes. $\mathrm{O}$ termo reflete as tendências sociais que indicam a busca de status por algumas pessoas e, de alguma forma, está relacionado com as divisões existentes na igreja de Corinto (POGOLOFF, 1992, p. 153-158; THISELTON, 2000, p. 164).

Apesar da identificação dos grupos representados nas designações "sábio", "escriba", "inquiridor", estes termos envolvem pleonasticamente o âmbito geral da sabedoria humana, uma perspectiva que é apoiada pela referência à "sabedoria do mundo" da questão retórica seguinte: "Porventura não tornou Deus louca a sabedoria do mundo?" (1,20b), que desenvolve o contraste entre as perspectivas divina e humana. As expressões "deste mundo" e "do mundo", às quais Paulo acrescenta as expressões "dos homens" e "segundo a carne" $(3,3)$, que ocorrem frequentemente em 1,18-4,21, modificam substantivos que representam aqueles que são conduzidos pelo presente sistema de valores, isto é, "este mundo" (POGOLOFF, 1992, p. 158; PICKETT, 1997, p. 63-64). Deus substitui a sabedoria humana da presente ordem por outro tipo de sabedoria, a mensagem da cruz de Cristo. A ordem atual da "sabedoria deste mundo" está sendo anulada pela iniciativa divina (THISELTON, 2000, p. 164-165). O "sábio", o "escriba", o "inquiridor deste século" não têm mais lugar na nova era inaugurada pela crucificação de Cristo e, nesta estrutura de pensamento, os contrastes apocalípticos expressam a realidade do que significa a diferença entre estas duas ordens de mundo.

A citação da Escritura assinala a destruição e anulação da sabedoria da elite intelectual "desta era", das pessoas que estavam comprometidas com a "sabedoria de palavra" $(1,17)$ e eram responsáveis pelas divisões na igreja (1,10-13), além de indicar que tal elite não possui o status que afirma possuir. Os fundamentos utilizados para fundamentar o seu status desintegram-se. A promessa da Escritura se atualiza (1,19): Deus destrói, no coração da sua sofisticação, a sabedoria "deste mundo", representada pelo sábio, escriba e inquiridor "deste século" (1,20a) ao torná-la loucura. "Sábio", "escriba" e "inquiridor" tornam-se "os que estão a caminho da perdição" $(1,18)$, isto é, aqueles que estão a caminho da destruição escatológica que Deus realizará no julgamento final (HEIL, 2005, p. 32; FEE, 1984, p. 71).

A promessa da Escritura ressignificada por Paulo torna-se explícita quando Paulo declara o que significa a "sabedoria de Deus" $(1,21)$. Da "perspectiva de Deus", o mundo não conheceu a Deus por meio da sabedoria. Então "pareceu bem a Deus salvar os que creem por meio da loucura da pregação" $(1,18 a)$, 
isto é, nós, Paulo e seus destinatários, "os que estão sendo salvos" (1,18b). A "sabedoria deste mundo" e a "palavra da cruz" são apresentadas antiteticamente. Não há continuidade entre elas, pois estão em lados completamente opostos da divisão apocalíptica. A contraparte positiva à "sabedoria deste mundo" que Deus promete destruir e anular está explícita na declaração de Paulo de que o Cristo crucificado, o Cristo da "palavra da cruz" $(1,18)$, é "poder e sabedoria de Deus" $(1,24)$. O "poder" e "sabedoria de Deus", que salva os creem, vistos como loucura e fraqueza, são, paradoxalmente, mais sábios e mais fortes do que a sabedoria e poder humanos $(1,25)$. São mais fortes e mais sábios porque, de acordo com a promessa indicada na Escritura (1,19), Deus destruirá a sabedoria humana e a substituirá por sua sabedoria, que transforma e inverte o sistema de valores da "sabedoria deste mundo" (ADAMS, 2000, p. 112-113; HEIL, 2005, p. 32-33).

\section{Cristo crucificado, poder e sabedoria de Deus}

Paulo estabelece uma distinção entre a "sabedoria de Deus" e a "sabedoria deste mundo" ao afirmar que há dois modos de perceber e julgar a mensagem da cruz $(1,18)$. O primeiro modo, a perspectiva "dos que estão sendo salvos", é resultado do recebimento do "Espírito de Deus" e reconhece a cruz como "poder e sabedoria de Deus"; o segundo modo, a perspectiva "dos que estão a caminho da perdição", é ditado pelo "espírito deste mundo" e considera a "palavra da cruz" como loucura $(2,12)$. Como é a palavra da cruz que desmascara os fundamentos da sabedoria deste mundo ao assinalar os seus limites, Paulo desenvolve ainda mais a sua argumentação ao declarar que Deus utiliza a "loucura da pregação para salvar os que creem" $(1,21)$, mas desta vez em relação ao comportamento dos judeus, que buscam "sinais", e dos gregos, que buscam sabedoria, e consideram a cruz, respectivamente, escândalo e loucura (LAMPE, 1990, p. 119-120). A comparação entre "sabedoria" e "loucura" está também relacionada com a antítese poder-fraqueza: "Porque a loucura de Deus é mais sábia do que os homens, e a fraqueza de Deus é mais forte do que os homens" $(1,25)$.

Nestes versos, o uso de "porque" (1,22a) estabelece a ligação entre 1,21 e 1,22-24 e introduz os judeus e gregos numa mesma esfera de pensamento. Da mesma forma que "o mundo não conheceu a Deus por sua sabedoria" $(1,21)$, a busca por "sinais" e "sabedoria", respectivamente por judeus e gregos, tem como resposta a pregação do "Cristo crucificado, poder e sabedoria de Deus" (POGGEMEYER, 2005, p. 118-119). Na declaração: "nós, porém, anunciamos" $(1,23 a)$, a conjunção "porém" assinala a dinâmica da procura por sinais e sabedoria e a resposta do pregador que anuncia o "Cristo crucificado", enquanto o uso de "porque" $(1,22 a)$ assegura a intenção divina de "salvar os que creem pela loucura da pregação". O efeito positivo da cruz predomina nestes versos e a afirmação "Cristo, poder e sabedoria de Deus" é o seu 
ponto fundamental. Os chamados, "judeus e gregos", conferem à "palavra da cruz" um significado universal. "Judeus" e "gregos" refere-se tanto aos que rejeitam a palavra da cruz como "aos que são chamados" (1,22-24). Da perspectiva divina, esta mensagem é uma continuação da declaração de que a resposta de Deus à incapacidade da sabedoria humana em conhecê-lo é salvar "os que creem pela loucura da pregação" $(1,21)$. O uso de "porque" $(1,22)$ destaca a insistência do apóstolo em anunciar a mensagem que lhe foi confiada, não apresentar uma mensagem para satisfazer as exigências dos valores que conferiam prestígio na cultura greco-romana (POGGEMEYER, 2005, p. 119; LAMPE, 1990, p. 121).

A indicação de que os judeus buscam "sinais" e os gregos "sabedoria" não é acidental. A busca por sinais reflete expectativas messiânicas dos judeus. Eles sabiam que Deus tinha agido no passado, com "mão forte e braço poderoso", e que ele repetiria os eventos do êxodo com uma glória ainda maior, mas agora, a "palavra da cruz", que assinala a inauguração de um novo momento na história, lança uma luz inteiramente nova no significado dos sinais. No contexto de suas expectativas e da inversão final esperada, a busca por "sinais" de um fim iminente pelos judeus é compreensível. Deus agiu poderosamente a favor deles e suas expectativas em torno do Messias prometido, um libertador há muito tempo esperado, eram de que ele restauraria a glória anterior do povo de Israel ao agir novamente na sua história. Mostra-nos um sinal, eles exigiam de Jesus (Mt 12,38-39; Mc 8,11; Lc 11,16; Jo 6,30), dê validade às suas credenciais messiânicas por meio de manifestações poderosas. Desta forma, relacionar a manifestação messiânica com a proclamação da cruz constituía uma afronta. Sua percepção negativa indica ceticismo e incredulidade para com a "palavra da cruz", pois entendiam que a morte de Jesus, uma execução vergonhosa e humilhante, dificilmente constituiria um sinal da ação salvífica de Deus. Deus não enviou os sinais esperados, mas um Messias que foi crucificado. Para muitos judeus os "sinais do fim" eram compreendidos como uma inversão do seu destino político, então um Messias crucificado seria visto como afronta, escândalo (FITZMYER, 2008, p. 158-159).

Similarmente, o desejo dos gregos pela sabedoria é apresentado de forma negativa, pois consideram a mensagem da cruz como loucura. De fato, quem poderia culpá-los, pois ninguém antes deles conhecera tão grande desenvolvimento cultural. Eles buscavam a sabedoria que traria sucesso na política, nos tribunais, na filosofia, no comércio, numa vida autárquica e, especialmente, a aprovação ou admiração de seus respectivos pares (LAMPE, 1990, p. 122). A perspectiva de vida baseada nesses valores considera a "mensagem da cruz" uma afronta, pois a sabedoria humana considera loucura tudo o que é contrário a este modelo de vida. A "palavra da cruz" é também desprezada, pois a pessoa que Paulo proclamava havia aceitado um tipo de sofrimento e morte que eram considerados desonra e vergonha. A proclamação da "palavra da cruz" aos que buscavam honra e 
estima significava, portanto, uma grande afronta. Além disso, a renúncia à autarquia e a confiança posta inteiramente na ação de um "outro" significava a negação de tudo o que os gregos consideravam como caminho para o sucesso (FEE, 1984, p. 74-75; POGGEMEYER, 2005, p. 120-121; THISELTON, 2000, p. 170-171).

Os judeus, que buscam "sinais", e os gregos, que buscam sabedoria, estão, portanto, no mesmo patamar. A cruz de Jesus é escândalo e loucura para os judeus e gregos, porque "revela a ilusão do homem em pretender transcender a si mesmo e realizar a própria salvação, e em pensar que pode arrogar-se, até diante de Deus, a sabedoria, a piedade e a glória" (KÄSEMANN , 2003, p. 72). Mas Paulo não procura ocultar a afronta causada pela proclamação da realidade ofensiva de um Messias crucificado $(1,23)$. A narrativa da cruz envolve a vida de uma pessoa do mais baixo status social, um criminoso crucificado, que, paradoxalmente, "para os que são chamados", "judeus e gregos", significa "poder" e "sabedoria de Deus". A manifestação do poder e sabedoria de Deus tornam-se efetivas na própria forma de ação de Deus na cruz de Jesus, o Messias. Para "os que são chamados", o Cristo crucificado não significa escândalo ou loucura. "Os que são chamados", "os que estão sendo salvos" $(1,18)$, "os que creem pela loucura da pregação" $(1,21)$, isto é, judeus e gregos $(1,24)$, tornam-se a manifestação do poder e sabedoria de Deus $(1,18.21)$; a cláusula elíptica "Cristo, poder e sabedoria de Deus" $(1,24)$ é um aposto a "Cristo crucificado" $(1,23)$ : "a mensagem da cruz é poder para os que estão sendo salvos" $(1,18 b)$. A sabedoria de Deus $(1,24)$ está fundamentada na loucura pregação $(1,21)$, no anúncio do Cristo crucificado $(1,23)$, em quem Deus inaugurou uma nova forma de salvação (SCHÜTZ, 2007, p. 194-195).

Paulo não estabelece uma nova forma de conhecimento entre "os que creem" e "os que não creem". Cristo, "poder e sabedoria de Deus" $(1,24)$ é uma designação que poderia ter sido apresentada em 1,18, onde o paralelismo da sentença é interrompido pelo uso da palavra "poder" e não "sabedoria". Mas Paulo, ao referir-se a poder, prepara a declaração "Cristo, poder e sabedoria de Deus", procura evitar uma má compreensão do que significa sabedoria e sublinha a ligação entre a pregação e poder. A "palavra da cruz", para os que creem, é poder $(1,18)$. Cristo é "poder e sabedoria de Deus" $(1,24)$. A razão porque Cristo é agora conhecido como sabedoria e poder não significa que a incapacidade da humanidade em perceber a loucura e sabedoria de Deus foi corrigida $(1,21)$. Ela reconhece a loucura e sabedoria de Deus devido ao poder da proclamação da "palavra da cruz" (SCHÜTZ, 2007, p. 195-197), isto é, o evangelho $(1,21 ; 2,4)$. Deus salva "os que creem por meio da loucura da pregação" e os "judeus" e "gregos" participam indistintamente da salvação $(1,21.24)$. O evangelho que Paulo proclamou e por meio do qual os coríntios creram é a palavra da cruz (WOLTER, 2015, p. 118). 
É a proclamação do "Cristo crucificado", "sabedoria e poder de Deus", como evento salvífico, que faz com que a diferença entre "judeus" e "não judeus" seja superada. Uma nova comunidade é constituída em relação à aceitação ou rejeição desta proclamação. Os limites existentes até este momento entre judeus e gentios são derrubados. Novos limites são colocados, mas agora eles são definidos em relação à "palavra da cruz", o paradigma fundacional do novo mundo que foi criado para a humanidade. A sabedoria e o poder de Deus são revelados na cruz de Cristo (1,23-24). Estas afirmações expressam os aspectos positivos e negativos da inversão feita por Paulo da declaração de que a cruz é loucura: a cruz é o julgamento de Deus sobre o mundo e sua sabedoria e o Cristo crucificado é a sabedoria e o poder de Deus (1,23-24). "Sabedoria" e "poder", redefinidos pela "palavra da cruz", tornam-se a própria base da denúncia dos valores que a consideram como loucura (WOLTER, 2015, p. 119-120; PICKETT, 1997, p. 69).

A cruz era considerada loucura porque simbolizava fraqueza e vergonha, mas a discussão destes valores antitéticos com referência à identificação do poder de Deus com Cristo crucificado culmina na sua inversão. A forma como a "loucura" é apresentada em oposição ao "poder de Deus" indica que a comparação entre "sabedoria" e "loucura" está também relacionada com a antítese poder-fraqueza: "Porque a loucura de Deus é mais sábia do que os homens, e a fraqueza de Deus é mais forte do que os homens" $(1,25)$. Este verso sumariza e fundamenta tudo o que foi afirmado antes: a crucificação de Cristo é a instância fundacional da comunidade. A presença dos adjetivos comparativos "mais sábia" e "mais forte" revelam uma irônica inversão da realidade divina sobre o julgamento humano. As duas partes do verso são paralelas: "a loucura de Deus é mais sábia" espelha "a fraqueza de Deus é mais forte".

Da perspectiva humana, a crucificação é considerada loucura porque parece fraca e a fraqueza manifestada por Cristo na cruz parece absurda, mas há uma grande sabedoria na cruz. No início do texto, a "palavra da cruz" divide a humanidade entre "os que estão sendo destruídos" e "os que estão sendo salvos" $(1,18)$. 1Cor 1,19-24 mostra a humanidade à procura da sabedoria e o julgamento de Deus sobre ela. A princípio, Paulo não identifica a cruz com a sabedoria e a chama de poder, mas 1,22-24 aplica o epíteto "sabedoria" ao Cristo crucificado. Ele indica também tanto a perspectiva humana quanto a divina ao sentido da palavra "fraqueza", que tem grande força no contexto de Corinto, pois a comunidade experimentava divisões devido às disputas que envolviam o poder. Ninguém queria ser considerado fraco ou experimentar as consequências da fraqueza (POGGEMEYER, 2005, p. 126-127).

"Cristo crucificado", "poder e sabedoria de Deus" em ação no mundo é, portanto, a contradição final que Paulo apresenta ao concluir o seu argumento. Ele afirma isso e mantém intacta a linguagem paradoxal do parágrafo. A cruz é vista como loucura "aos que estão sendo destruídos", 
mas Deus é "mais sábio do que a sabedoria humana". A cruz é "loucura" e "fraqueza" segundo os padrões de pensamento "deste mundo", mas é também "sabedoria e poder de Deus". Este paradoxo repousa no fato de que a fraqueza e o poder de Deus são definidos em relação à cruz de Cristo. A cruz é poder na medida em que o "poder de Deus" é definido escatologicamente. Os valores indicados pelas antíteses loucura-sabedoria e fraqueza-força são substituídos pelos valores centralizados na cruz. Como estes valores não são estabelecidos a partir da avaliação humana, fraqueza assume um sentido positivo. Na cruz, símbolo de desprezo, Deus revela a sua sabedoria e poder (PICKETT, 1997, p. 71).

O poder salvador, o conteúdo do evangelho e a experiência de poder estão centralizados no Messias crucificado. O propósito e efeito da morte de Cristo são apocalípticos, pois inauguram uma "nova era" e libertam aos que respondem afirmativamente à "mensagem da cruz" do poder da "antiga era" (Rm 5,18.21; Gl 1,4-5). A autodoação de Cristo na cruz resgata a humanidade dos poderes apocalípticos hostis desta era má: o pecado, a morte, os espíritos elementares e demais poderes que escravizam. O que creem estão sob o poder da graça manifestada na cruz, que inaugura a nova criação "onde a amor de Cristo é poder e o princípio operativo" (Rm 5,12-21; 6,15; 2Cor 5,14.17; Gl 2,15-21). O poder salvador de Deus e a morte de Jesus estão intimamente relacionados. A proclamação, a "palavra da cruz" e a salvação estão conectadas. O poder de Deus torna-se realidade na proclamação do Messias crucificado (GORMAN, 2001, p. 277-278). Paulo não nega a fraqueza do Messias crucificado, mas é "em" e "como fraqueza" que Cristo é o poder de Deus. Ele é lugar da revelação do poder de Deus somente como fraqueza, como o crucificado. Cristo é o poder-na-fraqueza e a crucificação é a demonstração decisiva do poder de Deus. A compreensão desta realidade abre também o caminho para superar as disputas interpessoais, tornando-se a base a partir da qual os coríntios deveriam construir a concórdia e unidade da comunidade, fundada a partir da proclamação do "Cristo crucificado" (2,2; 3,10-11).

\section{Conclusão}

Neste artigo ficou demonstrado como, em 1Cor 1,18-25, Paulo apresenta o poder e sabedoria de Deus por meio de uma imagem incomum. O poder se manifesta como fraqueza e a fraqueza como poder. A declaração inicial do texto: "a palavra da cruz é loucura para os que estão sendo destruídos, mas poder de Deus para os que estão sendo salvos" $(1,18)$, indica que a proclamação da cruz está associada com a loucura pelos que "estão sendo destruídos" por estarem alienados do poder salvador de Deus. A citação da Septuaginta de Isaías 29,14 em 1,19: “Destruirei a sabedoria dos sábios e anularei a inteligência dos entendidos", fundamenta a declaração de que 
Deus se opõe a e destrói aquilo que normalmente a humanidade considera como poder e sabedoria. As questões retóricas: “Onde está o sábio? Onde o escriba? Onde o inquiridor deste século? Porventura não tornou Deus louca a sabedoria do mundo?" $(1,20)$, reafirmam o argumento paulino que enfatiza o propósito de Deus em "salvar os que creem pela loucura da pregação" $(1,21 b)$. Paulo refere-se ao escândalo e loucura que a "palavra da cruz" significa para judeus e gregos, mas afirma também que "os que são chamados", "judeus" ou "gregos", encontram em Cristo o "poder e a sabedoria de Deus" (1,22-24).

A sabedoria deste mundo está sujeita à crítica da palavra da cruz tanto em sentido epistêmico quanto salvífico, pois ela define o que é a realidade e o que é vida. Paulo questiona o valor da sabedoria deste mundo aos olhos dos coríntios e, ao mesmo tempo, atribui poder ao que era considerado um sinal de fraqueza. Ao fazê-lo, Paulo diz algo novo e, dentro do milieu cultural, epistemologicamente ofensivo com respeito da natureza da salvação. Não é a sabedoria do sábio que salva, mas o poder da cruz, uma formulação que parece sem sentido aos olhos da sabedoria deste mundo. A cruz tem, portanto, uma função crítica. Ela não usurpa o julgamento de Deus, mas o antecipa e, talvez, até o determine ${ }^{2}$. Como o poder da palavra da cruz podia ser esvaziado pelo "prestígio da palavra ou da sabedoria" ou pela "linguagem persuasiva da sabedoria" $(1,17 ; 2,1.4)$, Paulo esforça-se para tornar a cruz o foco da sua proclamação $(2,2)$.

Paulo apresenta a proclamação do Cristo crucificado no centro de sua argumentação porque por meio dela Deus escolheu salvar "os que creem" e também porque, numa situação de partidarismos, a cruz é o elemento unificador da comunidade cristã ${ }^{3}$. Para Paulo, ela constitui a marca distin-

\footnotetext{
${ }^{2}$ THISELTON, 200, p. 159, declara: "If the cross constitutes in some sense a criterion defined in terms of an act of God's judgement, the event of the cross cannot logically be separated from that anticipation of the truth and reality which presupposes a finality or definitiveness otherwise reserved in principle for the revelation of God in the last days. Whether, in view of a difficult conceptual history, we prefer to speak of the context of apocalyptic (...) or simply more broadly of a context of eschatology, the wisdom-folly, human wisdom versus divine acts sets of contrast imply the 'reversals' which the Synoptic tradition characterize many eschatological pronouncements: the exalted will be brought to low, and the humble will be exalted (Luke 1:52)".

${ }^{3}$ De acordo com MITCHELL, 1992, p. 210-212, "Throughout 1:18-4:21 Paul refutes the false wisdom of the Corinthians which is, unfortunately, more like 'the wisdom of the world' $(1: 20 ; 2: 6.13$; $3: 3.19 ; 4: 10)$ than God's wisdom, the wisdom of the cross. (...) The wisdom of the world is the set of values and norms which divide persons of higher and lower status into separate groups, a wisdom which prefers dissension to unity, superiority to cooperation. This wisdom is, paradoxically, foolishness. The cross, the symbol of the humility and lowliness of the Christ, is the true Christian wisdom, God's wisdom. It is characteristic of Paul's adept argumentation that he can draw simultaneously on the Christian kerygma and common political lore - and that he contrasts the two as he does. Paul grounds this exhortation by appeal to his own example: he did not teach the Corinthians human wisdom, but God's wisdom (2:1-7). God's wisdom has the power to unite all those who are called, both Jew and Greek (1:24; cf. 12:13), thus ending ethnic separation in the common acceptance of the scandal of the cross".
} 
tiva da comunidade cristã como um sistema alternativo de valores. 1Cor 1,18-25 é uma narrativa das origens, a origem da fé dos coríntios por meio da pregação do Cristo crucificado. A sabedoria revelada no Messias crucificado poderia ser chocante para a sensibilidade estética de muitas pessoas em Corinto, mas o poder e a sabedoria de Deus são revelados na fraqueza e loucura da cruz, uma dinâmica que é evidente para os que creem no Messias crucificado. A validade da "sabedoria deste mundo", base das divisões e orgulho dos coríntios, é questionada pela fraqueza proporcionada pela manifestação do poder de Deus na cruz do Messias (WANAMAKER, 2003, p. 125-126).

Deus manifesta-se no sofrimento e morte do Messias crucificado como o Deus que acolhe a humanidade, um evento paradoxal que antecipa e contradiz a ação e sabedoria humanas. Deus não utiliza o poder humano convencional, ou seja, demonstrações de força, sinais impressionantes ou sabedoria sofisticada. Deus torna a salvação efetiva através da cruz de Cristo, considerada loucura e fraqueza pela sabedoria deste mundo. A sabedoria e o poder revelados na cruz constituem o julgamento escatológico de Deus sobre o mundo e sua sabedoria. A sabedoria e o poder são também redefinidos pela "palavra da cruz", que é a base da denúncia dos valores que a consideram escândalo e loucura (PICKETT, 1997, p. 69). O poder e a sabedoria são componentes-chave no processo de formação da identidade: a sabedoria como um recurso cognitivo que gera a correspondência entre crença e comportamento; o poder como o que assegura que esta correspondência ocorra. Mas o poder pode ser exercido como dominação ou empoderamento na formação da identidade. Paulo o emprega como empoderamento, de modo que a identidade em Cristo da comunidade possa ser transformada e sua percepção de poder redefinida no contexto da fraqueza de Deus.

\section{Referências}

ADAMS, E. Constructing the World: A Study in Paul's Cosmological Language. Edinburgh: T \& T Clark, 2000. (Studies of the New testament and its World).

COLLINS, R. F. 1 Corinthians. In: HARRINGTON, D. J. (Ed.). Sacra Pagina Series. Collegeville, Minnesota: The Liturgical Press, 1999. v. 7.

CONZELMANN, H. 1 Corinthians. G. W. MacRae (Ed.). Philadelphia: Fortress Press, 1975. (Hermeneia).

FEE, G. D. The First Epistle to the Corinthians. Michigan: Grand Rapids, 1987. (The New International Commentary on the New Testament).

FIORENZA, E. S. Rhetorical Situation and Historical Reconstruction in 1 Corinthians. New Testament Studies, Cambridge, v. 33, n. 3, p. 386-403, jul./set. 1987. 
FITZMYER, J. A. First Corinthians: The Anchor Yale Bible Commentaries. New Haven: Yale University Press, 2008. (The Anchor Yale Bible).

GORMAN, M. J. Cruciformity, Paul's Narrative Spirituality of the Cross. Michigan/ Cambridge: Grand Rapids, 2001.

HEIL, J. P. The Rhetorical Role of Scripture in 1 Corinthians. Atlanta: Society of Biblical Literature, 2005.

HENGEL, M. Crucifixion: in the Ancient World and the Folly of the Message of the Cross. Philadelphia: Fortress, 1977.

INKELAAR, H-J. Conflict over Wisdom: The Theme of 1 Corinthians 1-4 Rooted in Scripture. Leuven/Paris: Peeters, 2011.

JUDGE, E. A. The Reaction against Classical Education in the New Testament. Journal of Christian Education, Michigan, v. 77, p. 7-14, July 1983.

KÄSEMANN, E. O valor salvífico da morte de Jesus em Paulo. In: KÄSEMANN, E. Perspectivas Paulinas. São Paulo: Teológica \& Paulus, 2003. p. 59-100.

LAMPE, P. Theological Wisdom and the 'Word About the Cross'. The Rhetorical Scheme in I Corinthians 1-4. Interpretation, Richmond, VA, v. 44, n. 2, p. 117-131, jul./set. 1990.

MITCHELL, M. M. Paul and the Rhetoric of Reconciliation: An Exegetical Investigation of the Language and Composition of 1 Corinthians. Louisville, Kentucky: Westminster/John Knox Press, 1992.

"Rhetorical Shortland in Pauline Argumentation: The Functions of the 'Gospel' in the Corinthian Correspondence'. In: JERVIS, L. A..; RICHARDSON P. (Eds.). Gospel in Paul. Studies in Corinthians, Galatians and Romans for Richard N. Longenecker. Sheffield: Sheffield Academic Press, 1994. p. 63-88.

PICKETT, R. The Cross in Corinth: The Social Significance of the Death of Jesus. Sheffield: Sheffield Academic Press, 1997.

POGGEMEYER, J. The Dialectic of Knowing God in the Cross and the Creation: An Exegetico-Theological Study of 1 Corinthians 1,18-25 and Romans 1,18-23. Roma: Pontificia Università Gregoriana, 2005.

POGOLOFF, S. M. Logos and Sophia. The Rhetorical Situation of 1 Corinthians. Atlanta, Georgia: Scholars Press, 1992.

SANDERS, E. P. Paul and Palestinian Judaism: A Comparison of Patterns of Religion. Phildelphia: Fortress Press, 1977.

SCHÜTZ, J. H. Paul and the Anatomy of Apostolic Authority. Louisville \& London: Westminster John Knox Press, 2007.

SEELEY, D. The Noble Death: Graeco-Roman Martyrology and Paul's Concept of Salvation. Sheffield: Sheffield Academic Press, 1990.

SHI, W. Paul's Message of the Cross as Body Language. Tübingen: Mohr Siebeck, 2008. (Wissenschaftloche Untersuchungen Zum neuen Testament 2. Reihe, 254). 
THISELTON, A. C. The First Epistle to the Corinthians. Michigan: Grand Rapids, W. B. E. Publishing Co., 2000.

VOSS, F. Das Wort vom Kreuz und die menschliche Vernunft. Göttingen: Vandenhoeck \& Ruprecht, 2002.

WANAMAKER, C. A. A Rhetoric of Power: Ideology and 1 Corinthians 1-4. In: BURKE, T. J.; ELLIOTT, J. K. (Eds.). Paul and the Corinthians: Studies on a Community Conflict. Essays in Honor of Margaret Thrall. Leiden: E. J. Brill, 2003. p. 115-137.

WOLTER, M. Paul. An outline of his Theology. Waco, TX: Baylor University Press, 2015.

Artigo submetido em 14.04.2018 e aprovado em 13.07.2018.

José Adriano Filho é Doutor em Ciências da Religião pela Universidade Metodista de São Paulo, UM/esP (2000). Professor de Exegese do Novo Testamento na Faculdade Unida de Vitória. Orcid.org/0000-0002-8157-4529. E-mail: joseadriano@faculdadeunida.com.br

Endereço: R. Desembargador Augusto Botelho, 688 - Ap. 502 29101-110 Vila Velha - ES 